\title{
The Molecular Identification Method for Purple Yam Cultivar Based on Genome RAPD Analysis
}

\author{
Liu Pangyuan, Song Shuhui, Zhao Hong, He Weiming, Wang Wenqi, Wang Huijie \\ National Engineering Research Center for Vegetables, Beijing, China \\ Email address: \\ liupangyuan@nercv.org (Liu Pangyuan)
}

\section{To cite this article:}

Liu Pangyuan, Song Shuhui, Zhao Hong, He Weiming, Wang Wenqi, Wang Huijie. The Molecular Identification Method for Purple Yam Cultivar Based on Genome RAPD Analysis. Science Discovery. Vol. 4, No. 3, 2016, pp. 161-164. doi: 10.11648/j.sd.20160403.11

Received: January 11, 2016; Accepted: May 16, 2016; Published: July 5, 2016

\begin{abstract}
Based on the limited understanding of the former researchers on RAPD marker, numbers of cultivars of purple yam were utilized to evaluate the application of RAPD in cultivar identification of purple yam. The results showed that RAPD was a stable DNA marker technique, and it could be scientifically and easily used in cultivar identification purple yam. The RAPD fingerprints of purple yam crops, which were derived from primers with different number of nucleotides length, were different in band number, polymorphism and band clarity. Basically, RAPD primers with S1255 can show DNA fingerprint clearly in purple yam for the generation, while RAPD primers with S1255 is more suitable purple yam crops.
\end{abstract}

Keywords: Purple Yam, RAPD, Cultivar Identification

\section{一种基于基因组RAPD分析的紫山药品种分子鉴定方法}

刘庞源, 宋曙辉, 赵泓, 何伟明, 王文琪, 王慧杰

北京市农林科学院蔬菜研究中心, 北京, 中国

邮箱

liupangyuan@nercv.org（刘庞源）

摘要: 针对RAPD技术的特点及其实际应用中易出现稳定性的问题, 本研究以来自中国不同地区八种紫山药的不同品种为 试材, 对RAPD技术在鉴定紫山药品种中的科学性进行了技术上的验证与分析。结果表明理想的反应条件能够保证RAPD 技术具有很好的稳定性, 是适用于鉴定紫山药品种的简易与理想的DNA分子标记技术。不同长度的引物的RAPD技术在几 种紫山药品种鉴定中体现出谱带清晰度以及数量等方面不同的特点。其中碱基数为S1255的引物在紫山药上的多态性较 高且谱带清晰, 以此为基础作为鉴定紫山药的不同品种。

关键词：紫山药, RAPD, 品种鉴定

\section{1. 引言}

紫山药（Dioscorea alata L.）, 又名大薯、参薯、 脚板薯、紫莳药、紫淮山。原产亚洲热带地区，属草本蔓 生性植物, 薯蓣科薯蓣属参薯种食用植物。世界上大薯的 种植地主要在西非、东南亚等地。是西非等国的主要粮菜 兼用的植物, 中国也是大薯原产地之一。大薯中有白肉和
紫肉品种, 紫肉品种是近几年因花青素的功效为大家所熟 知而逐渐增加。紫山药 (紫肉大薯) 作为一种新兴的蔬菜 资源, 对其研究还很有限。最早记载有薯蓣的中国最早的 一部药物学著作 “神农本草经” 中对山药就有记载, 被列 为上品, 可药食兼用的材料。到明李时珍的 “本草纲目” 中仍然没有明确的将两种植物分开, 仍然统称山药。 
先期进行的一些研究表明, 紫山药其营养及药用价值 除具有普通山药的优点外, 还富含花青素, 适于食用、药 用和加工利用。近年来, 随着人们对身体健康和营养保健 的关注, 对紫色作物有高度的青睐, 特别是对紫山药这种 药食同源、极具营养价值食品高度喜爱。表明紫山药有潜 在的开发价值, 既可作为蔬菜来食用, 又可以像怀山药作 为一种温和的药材。

紫山药是一种适宜短日照生长环境下生长的植物, 是 一种喜温类植物, 主要分布在我国南方沿海诸省的温暖地 带, 如浙江、江西、广东、广西、福建、海南、江西、云 南、湖南、台湾等地。紫山药品种大都是地方品种, 虽然 南方部分地区少量种植, 但栽培历史悠久。种植地区大都 丘陵山坡地带, 种植土壤土层深厚, 质地疏松, 有机质含 量高, 保水、保肥能力强, $\mathrm{pH}$ 值为4.5-6. 5, 呈微酸性。

紫山药因其肉质红中带紫而得名。紫山药块茎肥大, 单个块茎重500克左右, 最大达到2500多克, 肉质柔滑, 风味独特, 色泽亮丽鲜美, 营养丰富、肉质、色泽、味道、 黏度、气味、口感、营养成份分析等商品化指标在全省、 全国的山药中首屈一指。

紫山药的药用价值很高, 既可作餐桌上的佳肴, 又可作 保健药材, 据《本草纲目》记载, 经常食用紫山药, 可以降 低血压、血糖、抗衰益寿、健脑补智、增强人体免疫力和改 善性功能, 是益于脾、肺、肾功能的珍贵药食兼用资源。

随着人们对紫山药的日益关注，同时也激起了农民对 紫山药的种植热情, 南方种植紫山药的品种也有多种, 都 统称为紫山药, 从形态上很难准确鉴别, 因此快速准确地 鉴别紫山药品种是急需解决的问题。研究表明紫山药品种 之间在分子水平上存在着显著差异，从DNA水平上直接检 测其差异, 并用于无性系品种的鉴别最为可靠。因此, 对 紫山药进行遗传分析具有重要意义。

本研究提供了一种基于基因组RAPD分析的紫山药常 规品种分子鉴定方法。

\section{2. 材料与方法}

\section{1. 材料}

供试材料共 8 个, 分别引种于浙江、江西、福建、广 东、云南、台湾等地, 是当地的主栽品种, 请参见表 1 。

随机引物购自上海生工生物工程公司, $2 \times$ EasyTaq PCR SuperMix和DNA分子量标准Trans5K DNA Marker购于 北京全式金生物技术有限公司。

表1 紫山药品种及其来源。

\begin{tabular}{llll}
\hline 编号 & 所属种 & 品种 & 来源 \\
\hline 1 & 薯蓣科薯蓣属Dioscorea alata. & 紫山药 & 江西万载 \\
2 & 薯蓣科薯蓣属Dioscorea alata. & 紫山药 & 浙江温州 \\
3 & 薯蓣科薯蓣属Dioscorea alata. & 紫山药 & 福建武夷山 \\
4 & 薯蓣科薯蓣属Dioscorea alata. & 紫山药 & 广东惠州 \\
5 & 薯蓣科薯蓣属Dioscorea alata. & 紫山药 & 广东广州 \\
6 & 薯蓣科薯蓣属Dioscorea alata. & 紫山药 & 云南文山 \\
7 & 薯蓣科薯蓣属Dioscorea alata. & 紫山药 & 云南红河 \\
8 & 薯蓣科薯蓣属Dioscorea alata. & 紫山药 & 台湾 \\
\hline
\end{tabular}

\section{2. 取样及样品处理}

采用正常生长的紫山药品种, 每个品种 10 株, 每株 10 片新鲜幼叶放入冰盒, 置于 $-40^{\circ} \mathrm{C}$ 超低温冰箱中储存 $24 \mathrm{~h}$ 后冷冻干燥成粉末状 (由 SCANVAC 公司生产的 Coo $1 \mathrm{Safe}^{\mathrm{TM}}-55-4$ 真空冻干机冻干后, 用手轻微揉碎）, 将 其充分混匀;

\section{3. DNA提取及其纯度和浓度监测}

以幼叶干粉为材料, 取 $0.2 \mathrm{~g}$, 采用改良 $2 \times \mathrm{CTAB}$ (提 取缓冲液) 提取总DNA, 使用 $0.8 \mathrm{w} \%$ 琼脂糖对所获基因组DNA 的纯度进行检测, 利用蛋白核酸定量测定仪检测DNA浓度。

\subsection{1. $2 \times \mathrm{CTAB}$ 的配制方法}

缓冲液配置的成分及浓度

\begin{tabular}{|c|c|}
\hline 成分 & 浓度 \\
\hline Tris-HCl缓冲液（pH8.0） & $100 \mathrm{mmol} / \mathrm{L}$ \\
\hline EDTA-Na ${ }_{2}$ (EDTA二钠) $(\mathrm{pH} 8.0)$ & $20 \mathrm{mmol} / \mathrm{L}$ \\
\hline $\mathrm{NaCl}$ & $1.4 \mathrm{~mol} / \mathrm{L}$ \\
\hline CTAB & $20 \mathrm{~g} / \mathrm{L}$ \\
\hline DNA提取前加入 $\beta$-巯基乙醇 & $2 \mathrm{ml} / \mathrm{L}$ \\
\hline
\end{tabular}

表中显示 $2 \times \mathrm{CTAB}$ (提取缓冲液) 的成分, 按照这些 成分配置相应浓度, 达到使用目的。

\subsection{DNA提取方法}

(1) 取 $6 \mathrm{~m} 1$ 预热到 $60^{\circ} \mathrm{C}$ 的 $2 \times \mathrm{CTAB}$ 溶液于装有 $0.2 \mathrm{~g}$ 叶片 粉末的离心管中, $60^{\circ} \mathrm{C}$ 水浴 30 分钟, 间或轻摇几次, 使粉 末和溶液混匀; (2) 取出离心管, 待冷却后加入 $6 \mathrm{~m} 1$ 氯仿异戊醇（体积比 24: 1)，置于摇床上 30 分钟充分混匀; (3) $12000 \mathrm{rpm}$ 离心10分钟; (4) 将上清液转入新的离心管中, 加入 2 倍体积预冷 $\left(-20^{\circ} \mathrm{C}\right)$ 无水乙醇, 混匀, 在 $-20^{\circ} \mathrm{C}$ 冰 箱中放 30 分钟，使核酸沉淀成絮状;（5）室温下 $12000 \mathrm{rpm}$ 离心10分钟; (6) 弃上清, DNA沉淀风干后, 溶解于 $800 \mu 1$ 去离子水中, 作为PCR模板DNA, $-20^{\circ} \mathrm{C}$ 保存备用; 使用 $0.8 \mathrm{w} \%$ 琼脂糖对所获基因组DNA的纯度进行检测, 利用蛋白核酸 定量测定仪检测DNA浓度。使用Thermo公司NANODROP 2000 微量分光光度计直接测得DNA浓度, OD260/280的比值在 1.8-2.0之间, 0D260/230的比值在2.0-2.5之间, DNA浓度 大于 $10 \mathrm{mg} / \mathrm{ml}$ 。

\section{4. 引物篎选和RAPD分析}

在对紫山药进行RAPD分析的PCR扩增体系优化一一对 DNA模板量从 $5 \mathrm{ng}, 10 \mathrm{ng}, 20 \mathrm{ng}, 40 \mathrm{ng}, 60 \mathrm{ng}, 80 \mathrm{ng}$, $100 \mathrm{ng}$ 进行优化, 最总选择 $20 \mathrm{ng}$ 。然后, 选取八个（表 1) 在形态上差异比较大的紫山药品种进行RAPD 130 个引 物（见表2）篮选。

从得到的DNA指纹图谱中, 篎选出 1 个扩增带清晰、多 态性明显、重复性好的引物S1255 (TQACGCACGG), 进行PCR 扩增。 
表2 130 个随机引物编号及序列。

\begin{tabular}{|c|c|c|c|c|c|}
\hline 序号 & 引物编号 & 系列 & 序号 & 引物编号 & 系列 \\
\hline 1 & S1001 & TCCGCAACCA & 66 & S1266 & TCTCTAGGGG \\
\hline 2 & S1002 & САСТTCCGCT & 67 & S1267 & AGACCCTTGG \\
\hline 3 & S1003 & GGTTACTGCC & 68 & S1268 & CACCGATCCA \\
\hline 4 & S1004 & СТCCCCAGAC & 69 & S1269 & ACGGCCAATC \\
\hline 5 & S1005 & TTGCAGGCAG & 70 & S1270 & GGCGTATGGT \\
\hline 6 & S1006 & GTAAGCCCCT & 71 & S1271 & СTTCTCGGTC \\
\hline 7 & S1007 & ССCTACGGAG & 72 & S1272 & CCACTCGTGT \\
\hline 8 & S1008 & TTCCCGTGCC & 73 & S1273 & CCAAGCACAC \\
\hline 9 & S1009 & AGAACCGAGG & 74 & S1274 & CACCTCGACC \\
\hline 10 & S1010 & GGGATGACCA & 75 & S1275 & TGCTGACGAC \\
\hline 11 & S1011 & TCCGCTGAGA & 76 & S1276 & TCTTAGGCGG \\
\hline 12 & S1012 & TCCAACGGCT & 77 & S1277 & TTGGCATCCC \\
\hline 13 & S1013 & TGAGTCCGCA & 78 & S1278 & CACCACTAGG \\
\hline 14 & S1014 & TGTGGCCGAA & 79 & S1279 & AGCCTGGGGA \\
\hline 15 & S1015 & CTACAGCGAG & 80 & S1280 & GTCGAAACCC \\
\hline 16 & S1016 & CAAGGTGGGT & 81 & S1321 & GTGTGCCGTT \\
\hline 17 & S1017 & CAGTGGGGAG & 82 & S1322 & GGGAGGCAAA \\
\hline 18 & S1018 & GGGCTAGTCA & 83 & S1323 & CCAAGAGGCT \\
\hline 19 & S1019 & GGCAGTTCTC & 84 & S1324 & TCCCCAGGAG \\
\hline 20 & S1020 & GGAAGGTGAG & 85 & S1325 & AGTGCACACC \\
\hline 21 & S1021 & GGCATCGGCT & 86 & S1326 & AGGCATCGTG \\
\hline 22 & S1022 & AGCCGTTCAG & 87 & S1327 & ACGCGACAGA \\
\hline 23 & S1023 & GGGTCCAAAG & 88 & S1328 & AGTATGGCGG \\
\hline 24 & S1024 & CTATCCTGCC & 89 & S1329 & GGAAGTCCTG \\
\hline 25 & S1025 & GTCGTAGCGG & 90 & S1330 & CCAGGCTGAC \\
\hline 26 & S1026 & TGCCGCACTT & 91 & S1331 & TGATTGCGGG \\
\hline 27 & S1027 & ACGAGCATGG & 92 & S1332 & GGTCGGGTCA \\
\hline 28 & S1028 & AAGCCCCCCA & 93 & S1333 & GAGCACTGCT \\
\hline 29 & S1029 & TCGCTGGTGT & 94 & S1334 & CACGGGCTTG \\
\hline 30 & S1030 & TCGGGGCATC & 95 & S1335 & CAGCAATCCC \\
\hline 31 & S1031 & ACGGCGATGA & 96 & S1336 & GTCTGTGCGG \\
\hline 32 & S1032 & GACGCGAACC & 97 & S1337 & TGGGCTCTGG \\
\hline 33 & S1033 & ACGCTGCGAC & 98 & S1338 & GTGTGCAGTG \\
\hline 34 & S1034 & TGGTGCACTC & 99 & S1339 & CCCTGTCGCA \\
\hline 35 & S1035 & GACACAGCCC & 100 & $\mathrm{~S} 1340$ & ACACTCGGCA \\
\hline 36 & S1036 & AAGGCACGAG & 101 & S1341 & GTCCACCTCT \\
\hline 37 & S1037 & CCTCACGTCC & 102 & S1342 & TGCGAAGGCT \\
\hline 38 & S1038 & TCGCGGAACC & 103 & S1343 & TTTCCGGGAG \\
\hline 39 & S1039 & GGCAAAGCTG & 104 & S1344 & AAGGCTCGAC \\
\hline 40 & S1040 & ССТGTTCССT & 105 & S1345 & TCGCTGCGTT \\
\hline 41 & S1241 & CAGTGGTTCC & 106 & S1346 & GGCTTCGCAA \\
\hline 42 & S1242 & CAGGTCTAGG & 107 & S1347 & GACCGTCTGT \\
\hline 43 & S1243 & GACTGGGAGG & 108 & S1348 & AGGCTTCCCT \\
\hline 44 & S1244 & TTGCCTCGCC & 109 & S1349 & CCGATCCAAC \\
\hline 45 & S1245 & ACACCTGCCA & 110 & S1350 & CAAGGCCCCT \\
\hline 46 & S1246 & CCGTCCCTGA & 111 & S1351 & ACGCGCCTTC \\
\hline 47 & S1247 & ACTGCGACCA & 112 & S1352 & CTGTCGGCGT \\
\hline 48 & S1248 & TCCTCGTGGG & 113 & S1353 & CCGCTCGTAA \\
\hline 49 & S1249 & CCGTTAGCGT & 114 & S1354 & GGTGGGTAGA \\
\hline 50 & $\mathrm{~S} 1250$ & ACCTCCGGTC & 115 & S1355 & CCAAGAGGCA \\
\hline 51 & S1251 & CCAGATCTCC & 116 & S1356 & GGTGTGGTTC \\
\hline 52 & S1252 & СTGCCTAGCC & 117 & S1357 & GGTGATTCGG \\
\hline 53 & S1253 & CTGGTGGAAG & 118 & S1358 & ACCCCAACCA \\
\hline 54 & S1254 & GTGCCGCACT & 119 & S1359 & AACTTGGCCC \\
\hline 55 & S1255 & TGACGCACGG & 120 & $\mathrm{~S} 1360$ & TCATTCGCCC \\
\hline 56 & S1256 & CTCTCCGTAG & 121 & S1361 & TCGGATCCGT \\
\hline 57 & S1257 & AGCGACTGCT & 122 & S1362 & CCTGAACGGA \\
\hline 58 & S1258 & CCAGCTGTGA & 123 & S1363 & GGCTGTGTGG \\
\hline 59 & S1259 & ACCAAGGCAC & 124 & S1364 & CCAGCCTCAG \\
\hline 60 & $\mathrm{~S} 1260$ & ACATCAGCCC & 125 & S1365 & TCCGCATACC \\
\hline 61 & S1261 & GGGATGGAAC & 126 & S1366 & CCTTCGGAGG \\
\hline 62 & $\mathrm{~S} 1262$ & CCAACCCGCA & 127 & S1367 & CACGAGTCTC \\
\hline 63 & S1263 & ACGAAACGGG & 128 & S1368 & TCGCTCGTAG \\
\hline
\end{tabular}

\begin{tabular}{llllll}
\hline 序号 & 引物编号 & 系列 & 序号 & 引物编号 & 系列 \\
\hline 64 & S1264 & GGCTTCTGTC & 129 & S1369 & CCTTGACCCC \\
65 & S1265 & GAGCTACCGT & 130 & S1370 & ACTCTGGGGA \\
\hline
\end{tabular}

8 个紫山药品种采用 S1255引物, 在Gene Amp PCR System 9700PCR扩增仪上进行DNA扩增。采用 $20 \mu \mathrm{L}$ 反应体 系进行 PCR 扩增, 反应体系总体积为 $20 \mu \mathrm{L}$, 含 $10 \mu$ L2 $\times$ EasyTag PCR SuperMix (+dye) (北京全式金生物 技术有限公司 $)+2 \mu \mathrm{L} 5 \mathrm{mM}$ 引物 $+20 \mathrm{ng}$ DNA。

PCR反应程序为: $94^{\circ} \mathrm{C}$ 预变性 $5 \mathrm{~min} 30 \mathrm{~s}$; 接着 $94^{\circ} \mathrm{C}$ 变 性 $1 \mathrm{~min} 30 \mathrm{~s}, 40^{\circ} \mathrm{C}$ 复性 $1 \mathrm{~min}, 72^{\circ} \mathrm{C}$ 延伸 $2 \mathrm{~min}, 40$ 个循环; 最后 $72^{\circ} \mathrm{C}$ 后延伸 $10 \mathrm{~min}$ 。

扩增产物用 $1.6 \mathrm{w} \%$ 、含 $1 \mathrm{v} \%$ Golden view 的琼脂糖凝 胶电泳分离2-3h, 电压为 $6 \mathrm{~V} / \mathrm{cm}$; 在UV光下检测扩增结果 并通过凝胶成像系统 (Gel Doc XR $\mathrm{XR}^{+}$照相, 分别得到8种 紫山药的随机扩增多态DNA标准图谱（图1）。

\section{3. 结果与分析}

每个引物扩增产生了一种特有RAPD指纹图谱, 如图 1 是用S1255引物扩增的RAPD指纹图谱, 图中从左至右的图 谱编号分别为 M和 $1-8$, 其中 M: DNA分子量标准, Trans5K DNA Marker Go149 (北京全式金生物技术有限公司)；1-8: 紫山药品种编号, 见表 1 。对于每个供试紫山药品种的 5 个重复个体而言, 引物S1255分别扩增产生相一致的DNA 指纹图谱, 没有出现多态性, 从分子水平上说明, 无性繁 殖不影响供试植株的遗传结构。

由8种紫山药的随机扩增多态DNA标准图谱, 可以看到 S1255引物扩增出的特有DNA指纹, 8种紫山药品种扩增图 谱相互之间有明显不同, 可以同时区分出8种紫山药品种。

紫山药品种在中国还有很多, 目前收集品种还不完全, 还不能鉴定全部的紫山药品种, 只能给现在种植面积较大 的主要品种提供一个方便的鉴定方法, 此方法还有一定的 局限性，有待经一部提高。

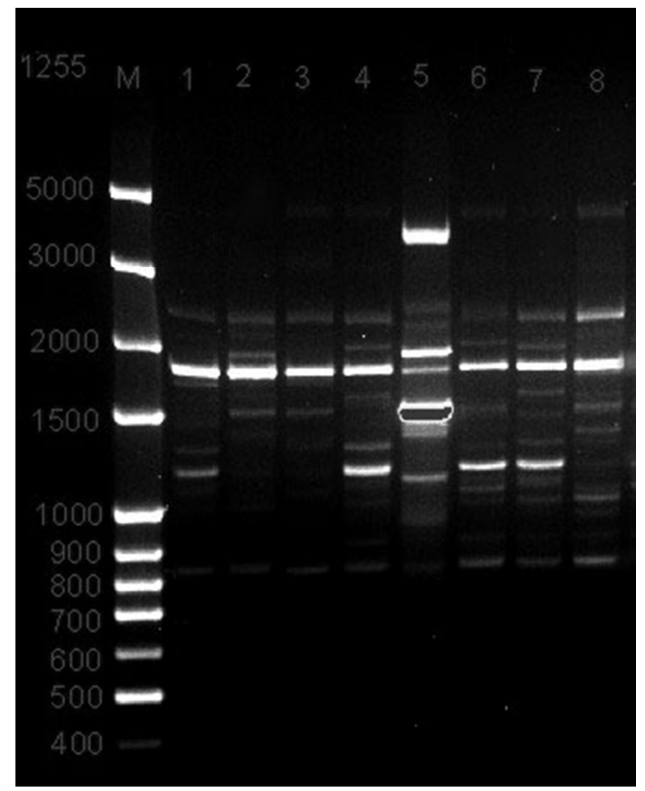

图1 8 个紫山药品种采用引物S1255 (TGACGCACGG) 扩增的RAPD标准图谱。 


\section{4. 鉴定方法的应用}

将待鉴定的紫山药品种按照上述步骤进行分析, 得到 所需要鉴定紫山药品种的随机扩增多态DNA图谱, 将此随 机扩增多态DNA图谱与标准图谱比较判定, 可以判断是否 为某种紫山药品种, 对紫山药生产提供品种选择的准确性, 确保紫山药生产的利益。

实例: 待鉴定紫山药为从云南市区农贸市场购买紫山 药, 编号为 9 号, 用S1255引物扩增的RAPD指纹图谱 (具体 步骤同前面所述）, 如图2所示, 图中从左至右的图谱编 号分别为M、1-8和 9 , 其中M: DNA分子量标准, Trans5K DNA Marker Go149 (北京全式金生物技术有限公司)；1-8：紫 山药品种编号，见表1；9：待鉴定紫山药。经过RAPD指纹 图谱鉴定比较, 判断待鉴定紫山药 ( 9 号) 与云南文山品 种 (6号) 的DNA图谱一致, 确定该待鉴定紫山药品种为云 南文山品种。

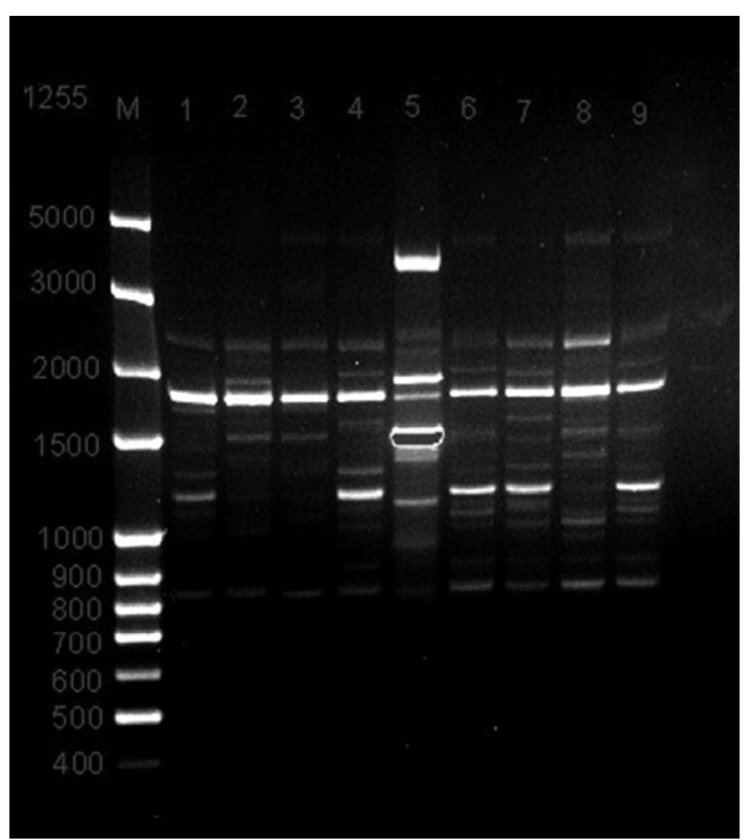

图2 8 个紫山药品种及待鉴定紫山药采用引物S1255（TGACGCACGG）扩增 的RAPD图谱。

\section{参考文献}

[1] An N, Guo H B, KEW D. Genetic Variation in Rhizome Lotus (Nelumbo nucifera Gaertn. ssp. nucifera) Germplasms from China Assessed by RAPD Markers [J]. Agricultural Sciences in China, 2009, 8(1): 31 39 .

[2] Yang RW, Zhou YH, Ding C B, et al Biologia Plantarum, Relationships among Leymus species assessed by RAPD markers [J]. Biologia Plantarum, 2008, 52(2): $237^{\sim} 241$.

[3] Wang Y J, Lu JN. The research on RAPD genetic markers of grape seedlessness gene [J]. Journal of Northwest A \& F University Na. t Sc. i Ed., 1996, 5(24): 10 20.

[4] Williams JG K, KubelikA R, Livak. J, et a. 1 DNA polymorphisms amplified by arbitrary primers are useful as genetic markers [J]. Nucl Acids Res, 1990, 18: $6531 \sim 6535$.

[5] Lin KH, Lai Y C, Li H C. Genetic variation and its relationship to rootweight in the sweet potato as revealed by RAPD analysis [J]. Scientia Horticulturae, 2009, $120(1): 2^{\sim} 7$.

[6] Cai Y L, Cao D W, Zhao G F. Studies on genetic variation in cherry germplasm using RAPD analysis[J]. Scientia Horticulturae, 2007, 111(3): 248 254.

[7] 马艳芝, 张玉星. 梨种质资源遗传多样性研究中的RAPD技术 引物篮选 [J]. 中国农学通报, 2009, 25(11): 30 33。

[8] 高道侠, 文海涛, 林励, 等. 江西酸橙不同栽培变种RAPD分析 [J]. 安徽农业科学, 2009, 37 (8) : $3457^{\sim} 3459$ 。

[9］李莉, 彭建营, 白瑞霞. 中国菄属植物亲缘关系的RAPD分析 [J]. 园艺学报, $2009,36(4): 475^{\sim} 480$ 。

[10] 杨向晖, 李平, 刘成明, 等. 枇杷属植物及其近缘属植物亲缘 关系的RAPD分析 [J]. 果树学报, 2009, 26(1):55 59。 